\title{
Increased ablation of Wisconsin ice in eastern north Greenland: observations and modelling
}

\author{
Carl Egede Boggild \\ Geological Survey of Denmark and Greenland, DK-1350 Copenhagen K, Denmark \\ Hans OERTER \\ Alfred-Wegener-Institut für Polar- und Meeresforschung, D-27515 Bremerhaven, Germany \\ TAPANi TUKIAINEN \\ Geological Survey of Denmark and Greenland, DK-1350 Copenhagen K, Denmark
}

\begin{abstract}
In Kronprins Christian Land at $80^{\circ} \mathrm{N}$ in eastern north Greenland, it has been observed that the surface of the Wisconsin ice is significantly darker than the Holocene ice found immediately upstream from a transition located $710 \mathrm{~m}$ from the ice margin. $\delta^{18} \mathrm{O}$ analysis has shown the dark surface is of Wisconsin origin. Deep ice cores from the Greenland ice sheet all indicate that the Wisconsin ice contains orders of magnitude more microparticles which could be the reason for the dark appearance of the Wisconsin surface.

Photographic documentation, spectral surface-albedo measurements and satelliteimage analysis all indicate a reduced albedo of Wisconsin ice. The effect of this reduced albedo is not confirmed by the ablation measurements. However, measurements of ablation variability within small test sites has documented that large errors will arise if only one stake per measuring point is used. Energy-balance calculations show ablation rates should be $10-70 \%$, i.e. $1.8-8.4 \mathrm{mmd}^{-1}$, respectively, less than experienced. Additionally, a satellite-image analysis shows even higher albedo contrasts $20-30 \mathrm{~km}$ to the south of our transect locality.

Immediately after the termination of the ice age, most of the surface in the ablation zone consisted of this low-reflectance ice. So, in the early Holocene, the dark ice of Wisconsin origin is likely to have resulted in higher ablation rates than previously considered. This may probably partly explain the fast rate of retreat/disintegration of the ice sheets in the Northern Hemisphere, after the termination of the Wisconsin ice age.
\end{abstract}

\section{INTRODUCTION}

In 1993, a field programme was initiated by the Geological Survey of Greenland (GGU) and the AlfredWegener-Institut für Polar- und Meeresforschung (AWI) at the ice margin in the southwestern corner of Kronprins Christian Land (KPCL) in eastern north Greenland (Fig. 1). Among other studies, one aim was to collect ice samples for $\delta^{18} \mathrm{O}$ analysis, in order to gain an insight into the climate history of this northeastern corner of the Greenland ice sheet (Oerter and others, 1995). For this purpose, a line of stakes was drilled into the ice with a 50 $\mathrm{m}$ spacing, in a surface transect from the very ice margin to $2 \mathrm{~km}$ up on the ice sheet. This line also served as a profile for ablation measurements, for ice-flow determination and for albedo measurements. It was observed that the surface nearest to the ice margin appeared somewhat darker than further up on the ice sheet. Furthermore, the two areas were divided by a sharp transition located at
$710 \mathrm{~m}$ inland. The isotope profile has shown that this sharp transition (Fig. 2b) is at the termination of the last ice age, i.e. the Wisconsin/Holocene transition about 11500 years ago (Oerter and others, 1995) (see also Fig. $3 a)$. Figure 2 shows surface elevation as well as reflectance in the spectral range $0.45-0.52 \mu \mathrm{m}$ derived from Landsat 5 TM channel 1 and from ground-albedo data. The satellite-image albedo retrieval will be described in detail later. In Figure 2b, the Wisconsin ice is the darkish zone to the west of the ice margin. Further to the west, there is an old Holocene surface with a high albedo, which becomes less reflective at a younger age (towards the west) with a surface reflectance down to 0.18 .

Deep ice cores from the Greenland ice sheet show Wisconsin ice contains 10-100 times more dust than deposited in Holocene time when concentrations were somewhat constant at a level of $0.1 \mathrm{mg} \mathrm{kg}^{-1}$ (Hammer and others, 1985; personal communication from C. U. Hammer). The high dust concentrations in Wisconsin time 


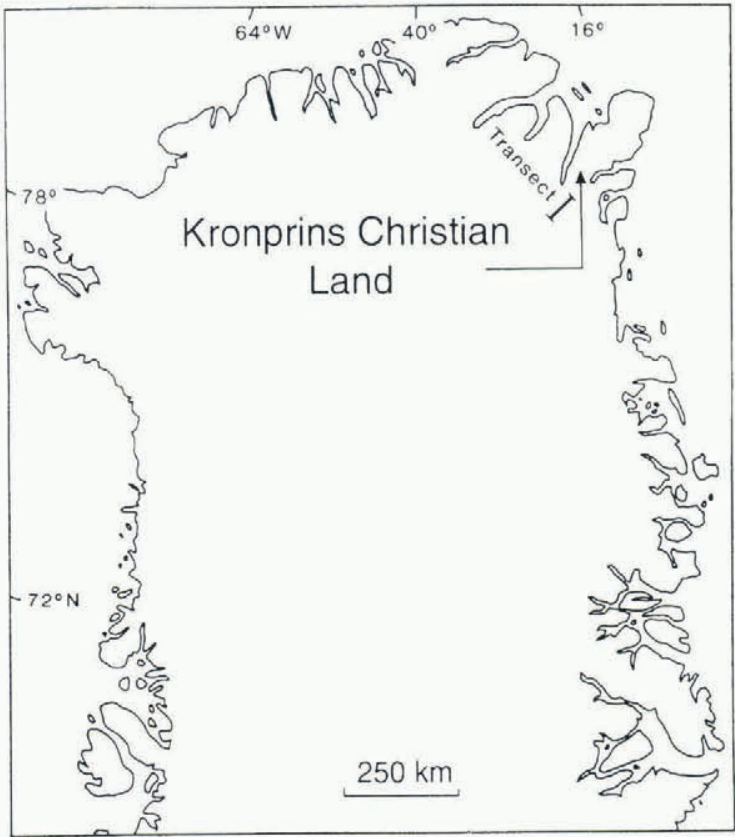

Fig. 1. Map of northern Greenland, indicating the area of investigation.

were associated with greater storminess and exposure of large unvegetated areas of the continents in the Northern Hemisphere (Steffensen, 1995). Dust deposition in Wisconsin time apparently did not significantly influence surface albedo in the accumulation zone, since frequent snow-accumulation events continuously buried the dust (Warren, 1982), which constituted about $90 \%$ of the Greenland ice sheet. In ablation zones, however, summer melting and forward flow caused the dust to accumulate on the surface, which increased radiative absorption and so further melting.

This paper reports, for the first time to our knowledge, increased ablation due to the reduced surface albedo of Wisconsin ice. Surface albedo values are derived from satellite-image processing of a Landsat 5 TM image where the albedo contrast between Wisconsin and Holocene ice is mapped along $50 \mathrm{~km}$ of the ice margin. Additionally, sensitivity experiments with an energybalance model and with climate data from the transect near the ice margin of KPCL are presented to quantify the effect of Wisconsin albedo values on melting rates, since "noisy" ablation data apparently do not provide a clear pattern of increased ablation.

\section{TRANSECT DATA}

Ablation measurements were carried out almost daily along the transect during the field seasons, i.e. 8-26 July 1993 and 1 July-5 August 1994. In 1993, the line was established with stakes at $50 \mathrm{~m}$ spacing from the ice margin to a point $1000 \mathrm{~m}$ on to the ice sheet, and the line was extended to $2000 \mathrm{~m}$ in 1994 . However, only $100 \mathrm{~m}$ spacing was maintained in 1994 . Figure $3 \mathrm{~b}$ and $\mathrm{c}$ gives the summer ablation during the above mentioned periods in 1993 and 1994, respectively.

Two types of albedo measurements have been carried
Table 1. Landsat 5 Thematic Mapper, spectral distribution of the sensors

\begin{tabular}{cc}
\hline Channel & $\begin{array}{c}\text { Spectral interval } \\
\mu \mathrm{m}\end{array}$ \\
& \\
\hline 1 & $0.45-0.52$ \\
2 & $0.52-0.60$ \\
3 & $0.63-0.69$ \\
4 & $0.76-0.90$
\end{tabular}

out along the transect. The first type were broad band and spectrally integrated measurements using a Kipp and Zonen CM7 pyranometer (albedometer) which gives single reflectance values in the spectral range from 0.3 to $2.8 \mu \mathrm{m}$. Figure $3 \mathrm{~d}$ and e shows how the reflectance varies along the transect in both 1993 and 1994.

More advanced reflectance measurements were carried out with a SE590 spectrometer (from Spectron Engineering) during the field campaign in 1994. This instrument provides reflectance in 252 discrete bands from 0.371 to 1.118 with a band width of $0.0021 \mu \mathrm{m}$. Data are collected digitally and stored on a portable PC, which also controls operation of the spectrometer. Figure 3f shows surface reflectance in four separate bands which match the spectral ranges of Landsat 5 TM channels 1-4. These bands have the spectral distribution listed in Table 1 .

It follows from Figure $3 \mathrm{f}$ that the Wisconsin/Holocene transition is clearly detectable in the shortest wavelengths,
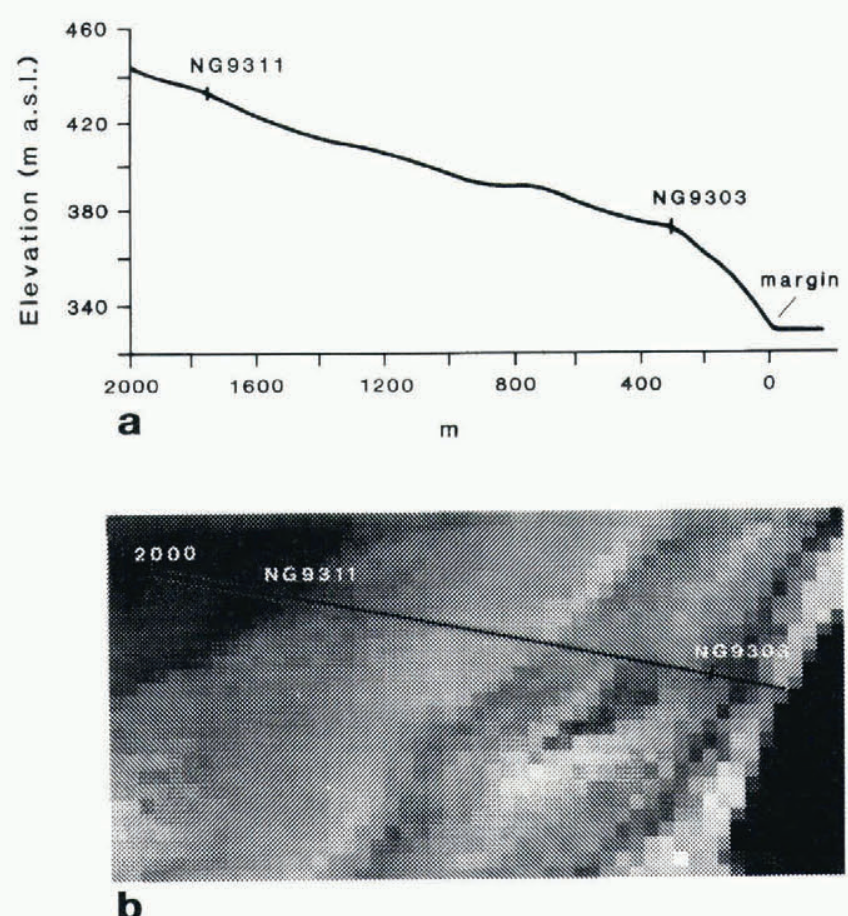

Fig. 2. Elevation profile (a) and surface reflectance (b) of the Wisconsin ice. The less-reflectant band covering the outermost $700 \mathrm{~m}$ of the transect line is Wisconsin ice. Surface reflectance is obtained by means of a Landsat 5 TM image from 25 July 1993. 

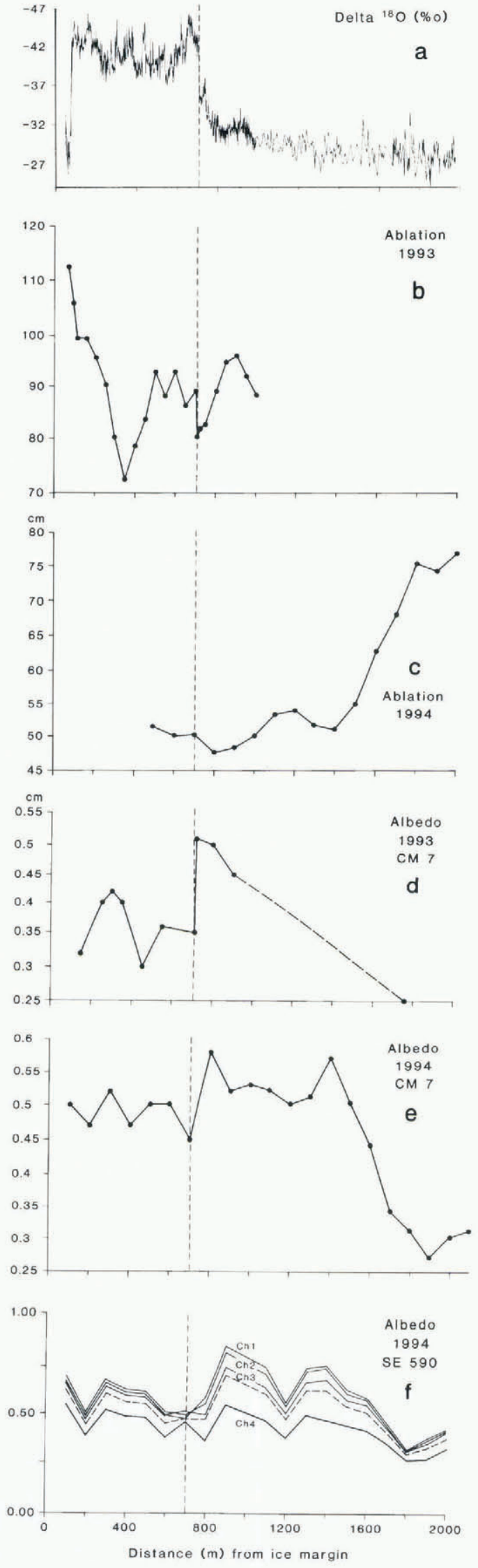

Fig. 3. Isotope profile (a), ablation profile from 1993 (b), ablation profile from 1994 (c), albedo profile from 1993 (d), albedo profile from 1994 (e) and spectral albedo profile $(f)$ along the transect line. The labels in (f) refer to channels on TM5.

i.e. similar to channels 1 and 2 of Landsat 5 TM. In the spectral range beyond $0.78 \mu \mathrm{m}$, i.e. of channels $4-7$ on Landsat 5 TM, the reflectance contrast between Holo- cene and Wisconsin ice is not visible, probably because of the large scatter of measured albedo values along the transect. It follows that the Wisconsin/Holocene transition can be detected with both spectrally integrated measurements (CM7) and with spectrally resolved measurements (SE590). But, the transition, as well as the overall difference in surface albedo between the two surfaces, is most clearly seen in the shortest wavelengths. The even lower reflectance observed in the upper ablation zone will be studied in further detail in the future. Apparently, distribution of dust on the surface greatly controlled the surface albedo here.

\section{ALBEDO DERIVED FROM SATELLITE IMAGE}

Combining satellite images with ground-truth data is a convenient way to map temporal as well as spatial variations of the surface albedo. Here, we do not consider the time aspect but will focus entirely on the albedo contrast between Wisconsin and Holocene ice obtained by Landsat 5 TM. The effect of the atmosphere on the surface albedo is normally corrected by a linear relation between planetary albedo $\alpha_{\mathrm{t}}$ (measured at the satellite) and the surface albedo $\alpha_{\mathrm{s}}$ by

$$
\alpha_{\mathrm{s}}=a+b \alpha_{\mathrm{t}} .
$$

The coefficients $a$ and $b$ can be determined by radiative-transfer modelling to compensate for the influence from the atmosphere, e.g. Koepke (1989) and Haefliger and others (1993). These coefficients can also be determined by regression fitting of ground-truth data to image data. The last approach has been used in this study. Measurements presented in Figure $3 \mathrm{f}$ have been compared with surface brightness values in the image of 25 July 1993 to retrieve a best-fit linear regression equation. The regression models were derived using a total of 20 data pairs in each channel along the transect. All models were found to be significant at a $10 \%$ level with a correlation coefficient ranging from 0.32 to 0.43 . Afterwards, the narrow-band albedo was calculated by integrating the surface albedo over the spectral range from 0.45 to $0.95 \mu \mathrm{m}$.

The best possible image covered the period of ground measurements from 20-22 July. However, no highquality images for the late summer of 1994 are available. We are well aware of the temporal variation of surface albedo, which is also seen in the difference between reflectance measurements in 1993 and 1994 given in Figure $3 d$ and e. But we consider this is of minor importance in relation to the surface-albedo gradient along the transect line. Moreover, the satellite image is precisely 1 year older to within $5 \mathrm{~d}$ of the spectrometer measurements, so the two ablation seasons can be considered equally advanced. The surface displacements in 1 year are less than $10 \mathrm{~m}$. Using a pixel size of $50 \mathrm{~m} \times 50 \mathrm{~m}$, which has been applied after geometric correction and resampling, the surface displacement over this 1 year is not likely to influence satellite-determined surface reflections in a detectable amount. Figure 4 shows the albedo contrast between Wisconsin and Holocene ice $40 \mathrm{~km}$ southward to an area where the ice margin becomes highly irregular and finally leads into the large 


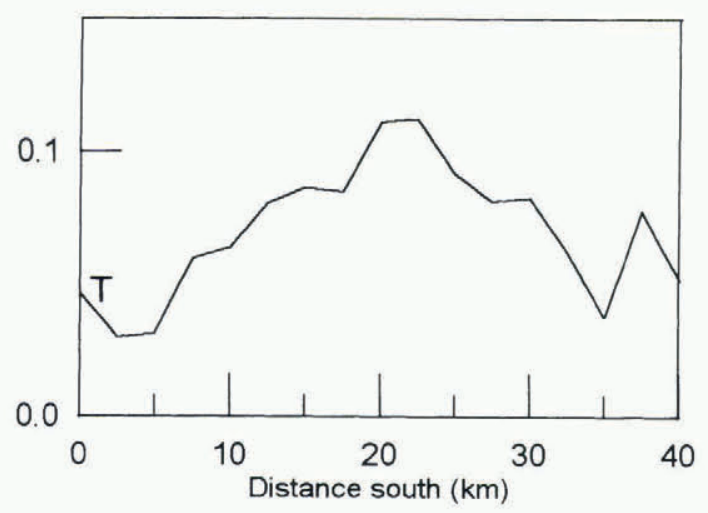

Fig. 4. Calculated albedo contrast between Wisconsin and Holocene ice along the margin, obtained from Landsat TM 5. "T" refers to the transect locality.

ice stream Nioghalvfjersfjorden from a point $1.5 \mathrm{~km}$ north of the transect. Despite large albedo variations of both Wisconsin ice (between 0.61 and 0.70 ) and of Holocene ice (between 0.54 and 0.65 ), the albedo contrast between the two different surface types is surprisingly consistent. It can be seen in Figure 4 that the location of the transect line is not ideal for studying albedo contrasts between Wisconsin and Holocene ice, since the largest albedo contrasts are to be found in the area from 20 to $30 \mathrm{~km}$ further south than the transect line. These larger albedo contrasts to the south are in agreement with our visual observations when this area was overflown on several occations upon arrival or departure from our field location. It is unlikely that difference in exposure to the sun can provide much of the albedo contrast described here, since the surface-slope and orientation variations over the transition are small, i.e. Figure 2a. It is therefore likely that the Wisconsin/Holocene albedo variations detected by satellite display real surface albedo variations.

\section{ENERGY BALANCE}

Climate data have been collected on a $3 \mathrm{~h}$ basis by an automatic meteorological station located about $100 \mathrm{~m}$ to the north of the transect line. This station has been in operation on a full-year basis since July 1993 and records continuously wind speed, wind direction, air temperature and atmospheric pressure. During both field campaigns, in 1993 and 1994, respectively, a separate data-logger was installed at the station for measuring global radiation. The data from the climate will be used in the following analysis of the effect of albedo variations assuming that climate does not change significantly over the short distance to and along the transect line. The energy balance used for calculating ablation is given by

$$
M+\delta G=Q(1-\alpha)+I_{\mathrm{i}}+I_{\mathrm{o}}+H+L_{\mathrm{v}} e
$$

where all fluxes are positive toward the surface and $M$ is the melt rate $\left(\mathrm{W} \mathrm{m}^{-2}\right)$. The component $\delta G$ is heat conduction into the ice, which Konzelmann and Braithwaite (1995) measured as being stable at around $17 \mathrm{~W} \mathrm{~m}^{-2}$ during almost 1 month in July 1993 at a locality about $100 \mathrm{~m}$ north of NG9303 (Fig. 2) in the Wisconsin ice. $Q$ is the global radiation, $\alpha$ is the surface albedo, which is measured along the transect as previously described. $I_{\mathrm{O}}$ and $I_{\mathrm{i}}$ are the outgoing and incoming longwave radiation, respectively. $H$ and $L_{\mathrm{v}} e$ are the turbulent fluxes of the sensible and latent heat, respectively. The turbulent fluxes are computed using the Monin-Obukhov similarity theory. The computational scheme has been adopted from Munro (1989). For this, some data on the aerodynamic effective surface roughness $z_{0}$ are needed. The value $0.006 \mathrm{~m}$ from detailed measurements in northeast Greenland at Britannia Glacier about $300 \mathrm{~km}$ to the south (Lister and Taylor, 1961) is used.

In order to determine the longwave radiation balance (4-100 $\mu \mathrm{m}$ ), some information quantifying the cloudiness is needed. Cloud cover has not been determined by synoptic observations. But this lack of observations is circumvented by inverting a model which normally estimates global radiation from information about cloudiness. By inverting this relation, it is possible to retrieve an estimate of the cloud cover based on theoretical calculation of the clear-sky radiation and by using the measured global radiation as input for the model (Boggild, 1991). Having calculated an estimated cloud cover, the incoming longwave-radiation component is obtained by using the Bolz type of equation, and the net longwave-radiation balance can be calculated from the fact that a melting ice surface emits $316 \mathrm{Wm}^{-2}$ in the longwave spectrum (Boggild, 1991).

Figure 5 shows the ablation calculated by means of the energy-balance Equation (2) and three sets of albedo values, namely, single-value measurements from the Kipp and Zonen CM7 pyranometer data, narrow-band integrated surface reflectances $(0.45-0.95 \mu \mathrm{m})$ obtained by the SE590 spectrometer and satellite-derived surface albedo. The calculated lack of ablation at some localities, based on the spectrometer data, is questionable since positive ablation rates have been observed along the whole profile in both field periods. Calculated ablation rates with CM7 data are 20-30\% higher than observations in the younger part of the Holocene ice at the stakes around $2000 \mathrm{~m}$ from the ice margin. Generally, the ablation values calculated by means of the satellitederived albedo are too low. It follows from observations and measurements that all three sets of results in Figure 5 give inter-stake ablation variations which are not

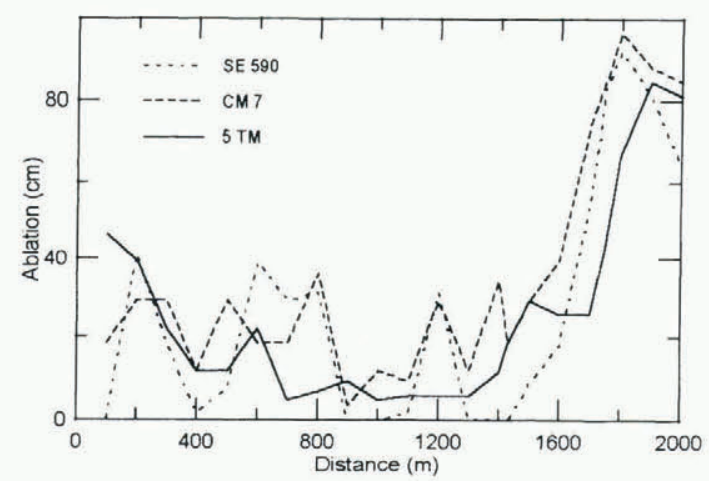

Fig. 5. Calculated ablation rates along the transect line by means of spectrally integrated albedo values (CM7) and spectrally resolved values (Spektro). 
confirmed by the ablation measurements (Fig. 3b and c). This does not necessarily indicate that the calculations or measurements are wrong, because the ablation readings are single-point readings which are only representative of the immediate vicinity of the stake. Since surface albedo has been shown to vary considerably within distances of about $1 \mathrm{~m}$, the true ablation difference between Wisconsin and Holocene ice may be hidden in the noise. Large spatial albedo and ablation variations have been analysed in detail by Konzelmann and Braithwaite (1995), who had a densely spaced stake farm located in the Wisconsin ice about $100 \mathrm{~m}$ from the 1993 transect. They found ablation rates varied up to $\pm 10 \mathrm{~mm} \mathrm{~d}^{-1}$ at neighbouring stakes. It is, however, known from photographic documentation, from the spectrometer data and from satellite images, that reflectance is less in late Wisconsin ice than it is in early Holocene ice. From the energy-balance calculations, it is apparent that the ablation rates are between $10 \%$ (with CM7 data) and down to $70 \%$ (by spectrometer data), i.e. 1.8 and $8.4 \mathrm{mmd}^{-1}$, respectively, less in the early Holocene ice compared to ablation rates in Wisconsin ice.

\section{CONCLUSIONS}

Three different sources, namely visual observations, spectrometer data and satellite images all show reduced reflectance of Wisconsin ice which most likely originates from the increased dust content of this ice. The lack or less frequent formation of cryoconite holes may also reduce the apparent surface albedo. The effect of reduced albedo in Wisconsin ice as compared to early Holocene ice does not appear in the ablation measurements along the transect. However, observations by Konzelman and Braithwaite (1995) in the same area show that single ablation measurements, using only one stake at each location, are not sufficient because of the large areal variability of ablation rate over a few metres distance. From energy-balance calculations, it is found that ablation in the early Holocene should be reduced by $10-70 \%$, i.e. $1.8-8.4 \mathrm{~mm} \mathrm{~d}^{-1}$. Only more detailed measurements can narrow this apparently wide range of uncertainty. In the area investigated, satellite images show even higher albedo contrasts to the south of the transect. A Wisconsin/Holocene albedo contrast is likely to be found in most places where Wisconsin ice is exposed. Reeh and others (1993) described the same type of surface in qualitative terms at Storstrommen in northeast Greenland. Increased ablation rates of Wisconsin ice have a significant palaeoclimatic implication since, in the period after the termination of the Wisconsin ice age, the whole ablation zone of all Northern Hemisphere ice sheets most probably consisted of the Wisconsin type ice. Enhanced ablation, following from reduced reflectance, most probably advanced the disintegration of the former ice sheets, despite a climate not much different from today.

\section{ACKNOWLEDGEMENTS}

This work has been supported by the Commission for Scientific Research in Greenland, by the Danish Natural Science Foundation, by the E.U. Environment programme and by the Nordic Council of Ministers. G. F. Hansen redesigned many of the computer print-outs into useful graphs. We thank State Geologist N. Henriksen for his useful comments on the manuscript, for his excellent organization of the logistics and for fruitful discussions at the base camp Centrum So, where he also provided a working place in the radio hut for preparation of this manuscript. N. Reeh and F. Jung-Rothenhäusler are thanked for participation in the field work.

\section{REFERENCES}

Boggild, C. E. 1990. En metode til beregning af genfrysning - langs en række profiler på Amitsulooq Iskappen. (Internal report, University of Copenhagen.)

Boggild, C. E. 1991. En smellende snepakkes masse- og energifluxe-belyst ved beregningsmetoder. (Ph.D. thesis, University of Copenhagen).

Haefliger, M., K. Steffen and C. Fowler. 1993. AVHRR surface temperature and narrow-band albedo comparison with ground measurements for the Greenland ice sheet. Ann. Glaciol., 17, 49-54.

Hammer, C. U., H. B. Clausen, W. Dansgaard, A. Neftel, P. Kristinsdottir and E. Johnson. 1985. Continuous impurity analysis along the Dye 3 deep core. In Langway, C. C., Jr, H. Oeschger and W. Dansgaard, eds. Greenland ice core: geophysics, geochemistry, and the environment. Washington, DC, American Geophysical Union, $90-95$. (Geophysical Monograph 33. )

Koepke, P. 1989. Removal of atmospheric effects from AVHRR albedos. J. Appl. Meteorol., 28, 1341-1348.

Koepke, 1992.

Konzelmann, T. and R.J. Braithwaite. 1995. Variations of ablation, albedo and energy balance at the margin of the Greenland ice sheet, Kronprins Christian Land, eastern North Greenland. J. Glaciol., 41 (137), 174-182.

Lister, H. and P. F. Taylor. 1961. Heat balance and ablation on an Arctic glacier. Medd. Gronl., $158(7)$.

Munro, D.S. 1989. Surface roughness and bulk heat transfer on a glacier: comparison with eddy correlation. J. Glaciol., 35 (121), 343348

Oerter, H., C. E. Boggild, F. Jung-Rothenhäusler and N. Reeh. 1995. AWI contribution to final report on Climate and Sea Level Change and the Implications for Europe, EU Environment 1990 94. Norwich, University of East Anglia. Climate Research Unit. (Final report, Contract EV5VCT91-0051.) [Unpublished.]

Reeh, N., H. Oerter and H. Miller. 1993. Correlation of Greenland icecore and ice-margin $\delta\left({ }^{18} \mathrm{O}\right)$ records. In Peltier, W. R., ed. Ice in the climate system. Berlin, etc., Springer-Verlag, 481-497. (NATO ASI Series I: Global Environmental Change 12.)

Steflensen, J. P. 1995. Microparticles and chemical impurities in ice cores from Dye 3, south Greenland and their interpretation in paleoclimate reconstructions. Ph.D. thesis, University of Copenhagen.

Warren, S. G. 1982. Optical properties of snow. Rev. Geophys. Space Phys., 20 (1), 67-89 